\title{
CAUSAL JUDGMENT IN ATTRIBUTIVE AND EXPLANATORY CONTEXTS
}

\author{
W.H. DraY*
}

I

In their book Causation in the Law, ${ }^{1}$ H.L.A. Hart and A.M. Honoré distinguish between the explanatory and attributive contexts in which causal questions typically arise. This distinction is important to Hart and Honoré partly because of their belief that causal inquiry in the law is generally attributive. ${ }^{2}$ Perhaps what they have in mind in making this distinction is more accurately characterized as two kinds of causal inquiry, or two kinds of causal judgment, or even two kinds of causal connection. In any event, the distinction between the explanatory and the attributive as it applies to causal judgments seems remarkably elusive, and its importance, whether for the law, history, or common sense is correspondingly obscure. Section two of this article is a brief discussion of the main lines of Hart and Honoré's account of the principles underlying the common sense notion of a cause. Section three is a critical examination of their distinction between the explanatory and attributive contexts of causal inquiry. The extent to which value judgments enter into causal selection is discussed in section four. The relation of attributions of responsibility to causal selection is discussed in section five. Section six concludes the article with a discussion of the suggestion that attributive causal inquiry may be distinguished by its focus on consequences.

Hart and Honoré offer an analysis of causal judgment in everyday life, history, and the law that has greatly influenced subsequent philosophical discussion of causal thinking. ${ }^{3}$ Their main concern is with a particular aspect of the way causes are talked about in these fields. When investigating some occurrence, it is common to distinguish between earlier events, conditions, and actions that can be singled out as the cause or causes of what happened, and those that, although relevant to the occurrence, are nevertheless seen as no more than part of the situation or circumstances, the background within which the truly causal conditions did their work. This distinction was scarcely

Copyright $\odot 1986$ by Law and Contemporary Problems

* Professor of Philosophy, University of Ottawa.

1. H.L.A. Hart \& A. Honoré, Causation IN THE LAw (1959) [hereinafter cited as H.I..A. HaRT \& A. HONORÉ].

2. Id. at 22-23.

3. See, e.g. J.L. Mackie, The Cement of the Universe: A Study of Causation $117-42$ (1974); M. Mandlebaum, Гhe Anatomy of Historical Knowledge 49-79, 199-204 (1977). 
noticed by philosophers before John Stuart Mill ${ }^{4}$ in the mid-nineteenth century, and was hardly treated as an interesting philosophical problem before R.G. Collingwood ${ }^{5}$ discussed it in the 1930's. Hart and Honoré contrast causes with "mere" conditions. This contrast is important because differences in causal diagnosis are often traceable to disagreements about which relevant conditions should be singled out as genuine causes of an occurrence rather than to disagreements about which conditions were relevant to the occurrence.

Hart and Honoré's persuasive account of the principles underlying this contrast begins with the general, common sense notion of a cause. Both lawyers and historians, they point out, show considerable respect for common sense ways of thinking about the natural world and human affairs. ${ }^{6}$ For common sense, the most general and pervasive notion of a cause is that of something which intrudes into a settled state of affairs or which interferes with ongoing processes. They claim to find two more specific principles employed in the selection of causes. ${ }^{7}$ The first is to select as causes highly abnormal antecedent conditions over equally relevant but normal ones. For example, in an area where hurricanes are unprecedented, if one unexpectedly arrives, it is the hurricane itself that will be considered the cause of the ensuing damage, not the unsurprising fact that those living in the area failed to hurricane-proof their houses. By contrast, if the same damage occurs in an area where hurricanes are common, it is not the hurricane but the inhabitants' strange fecklessness that will naturally be seen as the cause. Hart and Honoré's second specific principle is that, where highly voluntary human actions are among the antecedent conditions relevant to a given result, these will have a special claim to be considered causes. Thus, if someone knows that a hurricane is on the way, and deliberately weakens the bracing of his neighbor's roof, it is his voluntary intervention rather than the hurricane that will be considered the cause if the roof collapses.

Hart and Honoré very usefully emphasize that a characteristic feature of causal inquiry in law and history may be obscured if the application of either of these principles is represented as simply the selection of appropriate conditions from a temporally antecedent, jointly sufficient set. ${ }^{8}$ When searching for the cause of an occurrence, an investigator often faces the problem of how far back he needs to go along a series of conditions, each of which is sufficient for the next. In the example where the neighbor deliberately weakened the roof, a set of conditions sufficient for what happened which included the roof's weakened state presumably existed just prior to the roof's collapse. But it would be natural in many contexts for someone looking for the cause of the collapse to look right through any such

4. J.S. Mill, A System of Logic, Ratiocinative and Inductive 237-41 (8th ed. 1890).

5. Collingwood, On the So-Called Idea of Causation, 38 Proc. Aristotelian Soc'y 85 (1937-1938).

6. H.L.A. HART \& A. Honoré, supra note 1, at 1, 8.

7. Id. at 123-24.

8. Id. at $41-47$. 
set of conditions to the action of the person who weakened the roof, since this satisfies our paradigm notion of a cause. Therefore, according to Hart and Honoré, abnormal conditions and voluntary actions tend to function as temporal termini in causal inquiry. They are something back to which we are generally prepared to trace causal series, and back through which we are reluctant to do so. Although Hart and Honoré only consider examples drawn from everyday life and from the law, their analysis also throws a good deal of light on causal controversies in history, notably those in which the issue is whether the causes of something like a war or revolution were long-term or short-term.

\section{III}

Sometimes when we ask about the cause of an occurrence, Hart and Honoré observe, it is because we do not understand why it happened. ${ }^{9}$ In the case of a plane crash, for example, it may be only during a subsequent investigation that it is discovered that the craft was struck by lightning or had some serious mechanical fault. The investigator may thus find a causally selectable factor in a set of conditions close in time to the result. Alternatively, he may trace the cause back to the negligence of someone in the ground maintenance staff who failed to correct the fault, a condition that, as Hart and Honoré put it, offers us a fuller or more satisfactory explanation. But in still other cases, the causal question is raised when there is no question about what took place. This is typically the case when the relevant antecedent conditions include more than one that exhibits the kind of feature that leads to its selection as a cause. The question then is whether the claim of one of these conditions to causal status can be sustained in the light of the claim of the other. For example, in the case of the plane crash, it may be known from the outset that there was a procedure the pilot could have used to correct the mechanical fault, and that he did not use it. But it may be unknown whether the circumstances of his omission were such that the eventual crash should be attributed to this pilot error, rather than the more remote negligence of the mechanic. It is natural to say that the aim of the inquiry in such circumstances is less to explain than to attribute responsibility for what occurred. Consequently, it is natural to begin talking of two sorts of causal judgment, explanatory and attributive. Lawyers, and to a lesser degree historians, are especially concerned to make judgments of the latter sort.

But if this example offers a fair illustration of the distinction that Hart and Honoré want to note, it is important to see that, in one important sense, there is no discoverable contrast here between different sorts of causal judgment. In both explanatory and attributive cases, the criteria for selecting the specific causal condition are the same. In the explanatory inquiry, the failure of the mechanic would presumably be selected as the cause because, unlike the sheer physical abnormality of the mechanical fault, this was an abnormal exercise of

9. Id. at 22 . 
free human agency. In other words, on the criteria of abnormality and voluntariness, this is the point to which, but not through which, we trace the causal series in search of a satisfactory causal explanation. This may not be done in the attributive context envisaged because of our knowledge of the later human intervention-the pilot's failure to take appropriate remedial action. But if the pilot's error is causal enough in the attributive case to justify not looking back to still more remote conditions, it is surely causal enough to justify not doing so where the concern is not to attribute but to explain. In other words, if after an explanatory inquiry has resulted in the judgment that the cause of the crash was the mechanic's negligence, a later attributive inquiry concludes instead that it was the failure of the pilot, the different results will not be a consequence of appropriately different kinds of causal reasoning in the two cases. It will be a consequence of a mistake in causal reasoning in at least one case. If the conclusion in the attributive case is sound, this will require a revision of the original causal explanation. There are simply no resources in Hart and Honoré's theory for distinguishing causal judgments according to whether the interest or ultimate aim of the investigator is explanatory or attributive.

Hart and Honoré could be interpreted to suggest otherwise. For example, in illustrating the special interest of an explanatory inquiry, they sometimes slip into talking about the need to discover first how the result came about before raising attributive questions, as if an explanatory inquiry is concerned only with identifying all the relevant conditions before facing the question of which condition to regard as the cause for attributive purposes. ${ }^{10}$ But they talk just as often about explanatory inquiry seeking to discover why a result occurred, and they do this in contexts where it is clear that what they have in mind is not simply a noncausally selective answer to a why question, but a causally selective one." ${ }^{1}$ From the very beginning, they represent explanatory inquiries as searching out conditions which are properly selected as causes. And their idea of an attributive inquiry does not introduce any selective principle not already adumbrated for such causally explanatory ones.

\section{IV}

Does the reiterated association of the idea of an attributive inquiry with that of assigning responsibility suggest a principle for selecting causes? Is the move from explanatory to attributive contexts a move from purely factual to evaluative, and even moralistic concerns? Hart and Honoré do say that lawyers and historians need not become "moralists" in either context of inquiry. "2 This seems to mean only that to select a person or his action as the cause of some harmful result is not identical to judging him blameworthy. People are not always blamed for what they cause, nor are they always the cause of that for which they are properly held responsible. As Hart and

\footnotetext{
10. Id. at 22 .

11. Id. at $32,34,37$.

12. Id. at 59,73 .
} 
Honoré apply the criteria of abnormality and voluntariness in explanatory and attributive cases, they are far from value free. There is little hope of basing a firm distinction between the two kinds of inquiry on the presence or absence, or even the relative presence or absence, of value judgments in them.

In the contexts Hart and Honoré have in mind, value judgments enter into judgments of abnormality because to judge something abnormal requires the selection of a standard of comparison; and there may be no value-free way of showing that a certain standard is the one that ought to be employed in a particular case. ${ }^{13}$ They underline this fact without explicitly drawing the conclusion. To use one of their own examples, ${ }^{14}$ if a famine occurs in an underdeveloped country, a local peasant may quite naturally see it as caused by a drought that year, since with the rainfall that usually accrues, crops are adequate. While not denying the indispensable role of the drought, officials of the World Food Authority may look right through this condition to find the cause of the famine in the government's failure to accumulate food reserves. This result is more likely if it is well-known that drought occurs in the region from time to time. The standard by which the peasant identifies the relevant abnormality is the ordinary course of nature as he experiences it. The standard employed by the Authority is what governments do (or even what they ought to do) in circumstances where drought happens often enough to require preventive measures. In fact, value judgment enters into the selection of causal conditions here in two ways. The peasant evidently expects little from his government; given what he knows of it, he sees its omission as perfectly normal. But the Authority will not let the government off so easily. It will not accept the past behavior of a particular government as an appropriate standard of comparison in this case. It will insist on contrasting the omission in question with what would generally be done by governments with comparable responsibilities and powers. The Authority's standard is thus more demanding morally than that of the peasant. Value judgment also enters in when the Authority treats the drought as normal even though the peasant treats it as abnormal. In the Authority's view, it is normal in the sense that it occurs frequently enough to impose obligations on those who are in a position to prevent it.

Because Hart and Honoré frequently observe, without offering any evidence, that the features of causal thinking in everyday life and in the law that especially interest them are found also in the causal thinking of historians, ${ }^{15}$ it is interesting to note a parallel to the case just examined in a controversy over the causes of World War II between two English historians, A.J.P. Taylor and H.R. Trevor-Roper. ${ }^{16}$ In a provocative book, ${ }^{17}$ Taylor denies what he calls the traditional view that Hitler's prewar policies aimed at

\footnotetext{
13. Id. at 33 .

14. Id. at 33 .

15. Id. at $2,8,10,21$.

16. This controversy was discussed in W. Dray, Perspectives on History 69-96 (1980).

17. A.J.P. Taylor, Thie Origins of the Second Worid War (1961).
} 
German aggrandizement caused the war. He contends that, although these policies were aggressive, they were perfectly normal for a country that was potentially the greatest power in Europe. What was abnormal, and the real cause of the war, was the failure of the other powers either to keep Germany weak when they could have done so or to facilitate her regaining her "natural weight" in the power system. Trevor-Roper objects that Hitler's policies were in fact far more aggressive than those of his predecessors and were inconsistent with the means available in the post-Versailles world for settling international disputes. ${ }^{18}$ Taylor's standard of comparison for judging the normality of Hitler's policies is based on several hundred years of European great power history, which he sums up in the slogan "powers will be powers." Trevor-Roper's standard is based on a considerably foreshortened period in which he sees higher norms of international behavior. This difference between standards of comparison in effect expresses a difference between cynicism and idealism about world politics: it is a difference in value judgments.

It is even easier to see the way Hart and Honoré's second criterion, voluntariness, involves causal inquiry in value judgments. As these authors point out, the notion of a fully voluntary action is not univocal: it is the notion of an action that is not defective in any one of a number of ways. ${ }^{19}$ First, and least problematically, an action is not voluntary if the agent lacks adequate bodily control or the means of expressing his will. It is also, and more interestingly, not voluntary when done in response to a threat, when the action is coerced, or done under pressing obligation, when the action is a matter of duty, or is the one real choice in a difficult situation. But to decide whether an action was in fact coerced, it is necessary to judge to what extent an alleged threat justified the agent's conclusion that he had to act as he did; and this requires an estimate of the importance of the interests threatened. If an action is more likely to be viewed as involuntary when a gun is pulled than when the "threat" consists of the promise of a frown, this difference surely has a moral basis. Similarly, whether an agent was in fact obliged to do what he did is a question that requires a judgment of the validity of the alleged obligation. For example, the driver of a borrowed car is not obliged to run over a pedestrian who gets in his way in the middle of a block because he promised the car's owner to use the brakes only at major intersections. Whether an agent had only one real choice is even more overtly a valuecharged matter. For Hart and Honoré, in an attributive context the problem is whether the intervention of a second agent was voluntary enough to "negative" the causal connection between the action of a defendant and a certain harmful result to which he has contributed a necessary condition. ${ }^{20}$ But this will require a value judgment in assessing the voluntariness of the second agent's action. The same will be true, however, in explanatory

18. Trevor-Roper, A.J.P. Taylor, Hitler and the War. Encounter, July 1961, at 88 .

19. H.L.A. HaRT \& A. HonORÉ, supra note 1, at 129-51.

20. Id. at 128 . 
contexts if the relative voluntariness of a contributory action becomes an issue.

A good example of the way this works in history can be seen in an explanation of the outbreak of the Mexican War in 1846 recently offered by the American historian, N.A. Graebner. ${ }^{21}$ The cause, Graebner argues, was the impatience of too many American citizens, and of President Polk in particular, to realize long-cherished territorial ambitions at the expense of Mexico. ${ }^{22}$ Although he concedes that the Mexicans were obstreperous, were unwilling to negotiate even genuine American grievances, and were prone to move their troops provocatively along the ill-defined border between the two countries, Graebner refuses to find any part of the war's cause on the Mexican side. ${ }^{23}$ He supports this refusal with the following argument. A strong power in conflict with a weaker typically gives the weaker only two choices: to fight or to capitulate. Since capitulation was unthinkable for reasons of national honor, which Graebner appears to find cogent, Mexico in fact had only one real choice. ${ }^{24}$ By contrast, the stronger power had three choices: to increase the pressure, to moderate demands, or to let things drift. ${ }^{25}$ This argument suggests that the Americans had freedom of action while the Mexicans were forced or obliged to do what they did. ${ }^{26}$ This is a clear instance of the operation of the voluntariness criterion of causal selection and the role of value judgment in its application.

If explanatory and attributive causal inquiries cannot be distinguished by saying that value judgment is involved in one and not the other, might it nevertheless be said that the second alone is moralistic in the sense of issuing in an explicit attribution of responsibility? This could be said only with important qualifications. For one thing, the expression "was responsible for" is sometimes used in asserting causal connection in explanatory contexts as well. Even in attributive contexts, the moral implications may thin out to the vanishing point where not only human actions but also natural events are said to be responsible for a given result. Indeed, as Hart and Honoré themselves put it, the attributive problem in legal contexts is frequently whether a certain harm can be attributed to an earlier action, in spite of a later intervention, or an abnormal conjunction of events and circumstances. ${ }^{27}$ In other words, the question is whether to attribute the harm to a person or to a thing.

Occasionally, our authors advise us to bear in mind that "was responsible for" has more than one meaning. ${ }^{28}$ For example, it sometimes means no

21. Graebner, The Mexican War: A Study in Causation, 49 PAC. Hist. Rev. 405 (1980).

22. Id. at 422 .

23. Id. at 408 .

24. Id. at 407 .

25. Id. at 420 .

26. Id. at 407 .

27. H.L.A. HART \& A. Honoré, supra note 1, at 23.

28. Id. at 61 . 
more than "was the cause of," in which case it is tempting to assume it is used nonattributively. ${ }^{29}$ At other times, even in Hart and Honoré's own discussion, its meaning extends as far as "was to blame for." 30 In both law and morals, however, we seem to need a sense that stops short of this-a sense which allows us to say that it is only with reference to what a person was responsible for that he ought either to be praised or blamed. In attributive contexts, the responsibility ascribed to persons falls short of praise or blame in this way, while asserting more than could be causally asserted of natural events. It is something like "answerability," or, in legal contexts, perhaps "liability."31 Yet it is of little help in analyzing the nature of the causal judgments made in attributive contexts to note that responsibility is ascribed in this sense, for causal judgment does not itself assert such responsibility. The reason why the judgment should be regarded as "attributive" thus remains obscure.

This problem is brought into sharper focus, without being solved, by Hart and Honoré's attack on the doctrine ascribed to "legal modernists" that the only so-called "factual" element in causal judgment is the certification of causes as conditions sine qua non. ${ }^{32}$ Associated with this doctrine, the authors assert, is the claim that designating the acts of one person as the cause of a result rather than the acts of another is simply the application of different assessments of their responsibility for the result. ${ }^{33}$ The "legal modernists" would refer to this application as simply a matter of "policy."

Hart and Honoré respond that to say that a person caused a given result is not to hold him responsible for it, but to give a reason for doing so. Because such a reason is not in itself a sufficient one, the judgments of causation and of responsibility will not always coincide. ${ }^{34}$ An example of this distinction is provided by a person in New York City who negligently lights a fire in his house which spreads to a neighbor's house and then down an adjoining row. ${ }^{35}$ The applicable law in this jurisdiction specifies that the incendiary is responsible only for damage done to the first of the additional houses affected. Although legal policy may cut off responsibility at a certain point, however, Hart and Honoré insist that it cannot similarly cut off causation. ${ }^{36}$ This means that an incendiary who is relieved of responsibility for the more remote damage may still have caused it, given the criteria ordinarily applied in causal judgment.

Of course, what Hart and Honoré, following the "legal modernists," call a "factual element" in causal judgment is somewhat less factual than this language may lead one to expect. For example, in raising the strictly causal

29. Id.

30. Id. at 60, 93-94.

31. See id. at 61 .

32. See id. at 269-71.

33. Id. at 270 .

34. Id. at 60-62.

35. Id. at 63,84. Hart and Honoré base this example on Ryan v. New York Cent. R.R., 35 N.Y. $210(1866)$.

36. H.L.A. HART \& A. HonorÉ, supra note 1 , at $85,87$. 
question, it will be relevant to ask whether some of the neighbors helped spread the fire, thus intervening in a causally relevant way. As we have seen, the question whether such interventions are voluntary or abnormal enough to sever the connection to further consequences may involve value considerations. However, the inquirer is not required to decide who was responsible for what occurred before reaching a causal conclusion, deriving therefrom a criterion of selection for the causal judgment itself.

\section{VI}

Is there no fundamental difference, then, between explanatory and attributive causal inquiries, or at any rate, none possessing the kind of theoretical importance that seemed promised by the word "attributive" and the close association of attributive inquiry with the idea of assigning responsibility? Inquiries which begin by being puzzled about what occurred can certainly be distinguished from those which are understood well enough before a cause is specified, calling the first sort explanatory, but only the second causally explanatory. A distinction also can be drawn between inquiries in which the condition that is eventually called the cause is not known, or not known to be relevant, at the outset, and those in which both its existence and its relevance are already known, although its causal status is not yet known. Inquiries which respond to the question "What caused this harm?" or even "How far back must we go to find the cause of this harm?" can be distinguished from those which respond to the still more complex question "Given a later action or set of circumstances, can this harm be said to have been caused by that still earlier event or condition?" And a distinction can be made between inquiries in which the goal is simply causal explanation and those whose ultimate purpose is to find out who or what was responsible for what was caused. None of these contrasts, however, offer any secure basis for distinguishing between two kinds of causal inquiry, causal judgment, or concepts of causal connection, one to be called explanatory and the other attributive.

There remains one possibility that is worth exploring. Hart and Honoré point out that in attributive contexts, the question is often, and even typically, framed not in the language of causes, but in the language of consequences. ${ }^{37}$ This is of significance for our problem because, as they show at a number of points, causal statements and corresponding consequence statements are not always interchangeable. Hart and Honoré give the example of the failure of a contractor to take appropriate measures against flooding, permitting an inundation of a plaintiff's property to continue longer than it needed to with consequently greater damage. ${ }^{38}$ It was concluded here that, although the damage was a consequence of the contractor's negligence, it could not plausibly be said that the latter was the cause of it: that was to be found in certain

37. Id. at 59-60.

38. Id. at $132-33$. 
"forces of nature." In considering such examples, Hart and Honoré sometimes contrast actually causing harm with merely occasioning it, the latter including cases where an agent merely allows something to happen or be done. ${ }^{39}$ In an explanatory inquiry, the question is always whether a certain action or some other condition actually caused the result, where this is taken to mean more than merely occasioning it. If the question in an attributive inquiry is always whether a result can be said to be the consequence of an antecedent action, and this can include its merely being occasioned by it, then, since the consequence relation incorporates more than the strictly causal one, the two sorts of inquiry become distinguishable on a comprehensible and applicable criterion.

This way of resolving the problem, however, would be highly prescriptive, given Hart and Honoré's own demonstration that consequence language is naturally used in explanatory contexts and that the full-blown language of cause is used in attributive contexts. ${ }^{40}$ For example, where someone was knifed and shot at approximately the same time, the question might arise, in an explanatory context, whether the ensuing death was due to the knifing or to the shooting. In a discussion of the causal significance of providing opportunities to act, Hart and Honoré themselves present a case where merely allowing harm is described as causing it. ${ }^{41}$ When a householder goes away, leaving his house in the care of a neighbor who negligently fails to lock the door one night, and a thief seizes the opportunity to steal the silverware, the cause of the loss, they quite plausibly say, was the neighbor's unfortunate omission. The causal reasoning here seems identical with what is later referred to as occasioning. The person whose omission is selected as the cause had certain responsibilities in the context envisaged and the harm he was supposed to prevent was normal enough to be commonly guarded against. Thus, although it may be true that it feels especially comfortable to use the language of consequences when ascribing responsibility, it would be sheer stipulation to make its use the identifying mark of attributive inquiry.

In conclusion, therefore, there is no such thing as attributive causal judgment or an attributive concept of causal connection; and if there is anything that can properly be called attributive causal inquiry, this seems to be so only in the sense that a causal inquiry of an explanatory sort may be pursued from the outset with a view to eventually raising the question of responsibility.

39. See id. at 179-87.

40. Id. at 61-62.

41. Id. at 55-56. 